\title{
Influence of the flooding speed of former lignite open pits on the stability of final slopes
}

\author{
Maria Lazăr, Florin Faur*, and Izabela Maria Apostu \\ University of Petrosani, Department of Environmental Engineering and Geology, University Street, \\ no. 20, Petrosani, Romania
}

\begin{abstract}
Flooding the residual gaps of former lignite open pits is often applied worldwide, offering opportunities for the use of the lake and the reclaimed land, as well as many benefits, ranging from the restoration of ecosystems to the development of the local economy. The flooding process is conditioned by the available quantities of water from natural and/or artificial sources. Flooding can be done either by natural methods (underground water inflow plus intake of water from rainfall and superficial drainage), or by natural and artificial methods (water adductions from superficial collectors). Unlike artificial flooding, natural flooding has the advantage of reduced costs, but it is a long-lasting process. Depending on the flooding speed, as a result of rising water level and saturation of rocks from the final slopes, geotechnical phenomena such as landslides may occur. The paper aims at establishing the dependence between the rhythm of raising the water level in the lake and the geotechnical behavior of the rock in the internal dump. Depending on this, there is a need to accelerate the flooding process through adductions, as the hydrostatic pressure manifested on the final slopes determines the increase of their stability reserve.
\end{abstract}

\section{Introduction}

Filling with water (flooding) is one of the possible ways of reusing the residual gaps of former lignite open pits, this practice having major long-term benefits regardless of the type of use of the formed lakes. Formation of a lake in a former open pit leads to the increase of ecological, productive, cultural, touristic and landscape value, and a land that undergoes a reclamation process can take on the new function more quickly, generating sustainable development of the region [1].

However, the rocks from the internal dumps will be in contact with water, and beyond the restoration of the aquifer resources, as the water level increases in the dump, determines the deterioration of their geotechnical characteristics (increasing the volumetric weight and reducing the resistance characteristics of the rocks) and the increase of the geotechnical hazards such as landslides [2]. These geotechnical hazards can be significant and it is necessary to ensure the security of the objectives in the influence areas at all stages of the project (flooding stage of the residual gap and the functional stage).

* Corresponding author: faurfloring@yahoo.com 
When flooding the residual gaps of former lignite open pits, with the rise of the water level in the newly formed lake, the stability of the final slopes can be negatively affected by pore water pressure and, eventually, by hydrodynamic pressures. Simultaneously there are positive effects on slope stability in submerged or partially submerged conditions. In this case the water exerts a hydrostatic pressure on the slope acting as a support prism [3].

Therefore, it is important to evaluate the stability of the final slopes of the residual gaps of former open pits (especially for the interior dump) both prior to flooding and at various stages of water level in the lake and in the dump. On the basis of stability analyzes, the sliding risk of the final slopes can be determined and effective solutions and measures for increasing the stability reserve and diminishing this risk can be established and applied.

\section{Short review on the international research}

Stability of open pit lake slopes after flooding remains an area of uncertainty. Geotechnical failures in slopes and banks of pit lakes are quite well documented, for example those at pit lake Pątnów [4], Zülpich Mitte [5] and Concordia lake near Nachterstedt [6, 7]. The main reasons for these failures were discovered after the incidents or remain unknown. To understand the causal link behind these phenomena it is necessary to perform mapping of the open pit lakes and compare the results to the original design.

Gathering all possible information about flooded pit lakes is necessary due to the size of future open pit lakes and greater consequences associated with their failure $[8,9]$. The complexity of the issues connected with open pit flooding requires preparation of comprehensive models consisting of geotechnical and groundwater components.

\section{Description of the flooding process}

The period of time required to flood the residual gaps is conditioned by the quantities of water available from the natural and artificial sources, respectively by the volume of the residual gap and can be carried out in two ways:

A. Natural flooding - this method uses the groundwater potential (the main source characterized by: flow, filtration coefficient, flow rate, piezometric level etc.) to which is added the water from precipitation and superficial runoff [10]. It has the advantage of low costs, but the complete flooding of a large residual gap can be long lasting.

B. Artificial flooding (or combined, as it involves both natural flooding and man made adductions) - is applied when, for technical, economic or security reasons, the flooding of the residual gaps is pursued as quickly as possible or when the water supply from natural sources is insufficient. It can be done by directing waters from vicinity through minimal hydrotechnical works (ditches), through channels or by pumping systems. It can also be achieved by using the potential of the artesian aquifer horizon through free-drainage drills [11]. It has a number of advantages: assumption of the future function of the land considerably faster, the possibility of establishing the level up to which it is appropriate to raise the water in the lake, the possibility of correlating the development works with the amount of deviated water in the residual gap. Disadvantages are represented by the high costs and the need to carry out hydrotechnical works of diversion or capture and pumping, which, even through a minimum volume have a negative impact on the environment [12].

\section{Stability of submerged slopes}

In the case of flooding the residual gaps of former lignite open pits, it is necessary to analyze the equilibrium state of the submerged or partially submerged slopes. 
The stability analysis for submerged slopes starts from the Fellenius method (how the sliding body is divided into the two prisms, then in vertical strips and how the forces act on each strip). In these cases, in addition to the pore water pressure, a hydrostatic pressure $S_{i}$ acts on the surface of the slope.

Because the force $S_{i}$ is perpendicular to the surface of the slope, it will act through vertical and horizontal components, which, in turn, decompose into normal and tangential components $[2,3,13]$. The forces acting on the slip surface in the case of submerged slopes are shown in Table 1.

Table 1. Component forces acting on a strip $[2,3]$.

\begin{tabular}{|c|c|c|c|}
\hline $\begin{array}{c}\text { Component } \\
\text { forces }\end{array}$ & $\mathbf{G}_{\mathrm{i}}=\mathrm{b}_{\mathrm{i}} \mathrm{h}_{\mathrm{i}} \gamma_{\mathrm{v}}$ & $\mathbf{S}_{\mathrm{i}}=\gamma_{\mathrm{w}} \mathrm{h}_{\mathrm{ia}} \mathrm{b}_{\mathrm{i}} / \cos \alpha$ & $\mathbf{U}_{\mathrm{i}}=\gamma_{\mathrm{w}} \mathrm{h}_{\mathrm{ia}} \mathrm{b}_{\mathrm{i}} / \cos \theta_{\mathrm{i}}$ \\
\hline Vertical & $\mathrm{G}_{\mathrm{i}}^{\mathrm{v}}=\mathrm{b}_{\mathrm{i}} \mathrm{h}_{\mathrm{i}} \gamma_{\mathrm{v}}$ & $\mathrm{S}_{\mathrm{i}}^{\mathrm{v}}=\gamma_{\mathrm{w}} \mathrm{h}_{\mathrm{ia}}{ }^{\mathrm{b}} \mathrm{b}_{\mathrm{i}}$ & - \\
\hline Horizontal & $\mathrm{G}_{\mathrm{i}}^{\mathrm{o}}=0$ & $\mathrm{~S}_{\mathrm{i}}{ }^{\mathrm{o}}=\mathrm{S}_{\mathrm{i}}^{\mathrm{v}} \operatorname{tg} \alpha$ & - \\
\hline Normal & $\mathrm{N}_{\mathrm{i}}^{\mathrm{G}}=\mathrm{G}_{\mathrm{i}} \cos \theta_{\mathrm{i}}$ & $\mathrm{N}_{\mathrm{i}}^{\mathrm{S}}=\mathrm{S}_{\mathrm{i}}^{\mathrm{v}} \cos \theta_{\mathrm{i}}+\mathrm{S}_{\mathrm{i}}{ }^{\circ} \sin \theta_{\mathrm{i}}$ & $\mathrm{N}_{\mathrm{i}}^{\mathrm{U}}=\mathrm{U}_{\mathrm{i}}$ \\
\hline Tangential & $\mathrm{T}_{\mathrm{i}}^{\mathrm{G}}=\mathrm{G}_{\mathrm{i}} \sin \theta_{\mathrm{i}}$ & $\mathrm{T}_{\mathrm{i}}^{\mathrm{S}}=\mathrm{S}_{\mathrm{i}}^{\mathrm{v}} \sin \theta_{\mathrm{i}}-\mathrm{S}_{\mathrm{i}}^{\mathrm{o}} \cos \theta_{\mathrm{i}}$ & $\mathrm{T}_{\mathrm{i}}^{\mathrm{U}}=0$ \\
\hline
\end{tabular}

Taking into account the forces manifested in the sliding process in the case of submerged slopes and the way they act on the slip surface, the stability coefficient will be determined by relation $1[2,3]$ :

$$
F_{s}=\frac{\operatorname{tg} \varphi \sum\left(G_{i} \cdot \cos \theta_{i}+S_{i}{ }^{\nu} \cdot \cos \theta_{i}+S_{i}{ }^{o} \cdot \sin \theta_{i}-U_{i}\right)+c \cdot L}{\sum \pm\left(G_{i} \cdot \sin \theta_{i}+S_{i}{ }^{v} \cdot \sin \theta_{i}-S_{i}{ }^{o} \cdot \cos \theta_{i}\right)}
$$

Notations in formulas and table 1: $G_{i}$ - strip's weight; $G_{i}^{v}$ - vertical component of the weight; $\mathrm{G}_{\mathrm{i}}{ }^{\mathrm{O}}$ - horizontal component of the weight; $\mathrm{S}_{\mathrm{i}}$ - hydrostatic pressure; $\mathrm{S}_{\mathrm{i}}^{\mathrm{v}}$ - vertical component of the hydrostatic pressure; $\mathrm{S}_{\mathrm{i}}{ }^{\mathrm{C}}-$ horizontal component of the hydrostatic pressure; $\mathrm{U}_{\mathrm{i}}$ - pore water pressure; $\mathrm{N}_{\mathrm{i}}$ - normal component of the forces; $\mathrm{N}_{\mathrm{i}}{ }^{\mathrm{G}}$ - normal component of the force of gravity; $\mathrm{N}_{\mathrm{i}}^{\mathrm{S}}$ - normal component of hydrostatic pressure; $\mathrm{N}_{\mathrm{i}}^{\mathrm{U}}$ normal component of pore water pressure; $\mathrm{T}_{\mathrm{i}}$ - tangential component of the forces; $\mathrm{T}_{\mathrm{i}}{ }^{\mathrm{G}}$ tangential component of the force of gravity; $\mathrm{T}_{\mathrm{i}}^{\mathrm{S}}$ - tangential component of hydrostatic pressure; $\mathrm{T}_{\mathrm{i}}^{\mathrm{U}}$ - tangential component of pore water pressure; $\alpha$-inclination of the slope (to the horizontal); $b_{i}-$ strip's width; c - rock's cohesion along the sliding surface; $\gamma_{v}-$ volumetric weight of the rocks; $\gamma_{\mathrm{w}}$ - specific weight of water; $\varphi$ - angle of internal friction along the sliding surface; $L$ - length of the slip surface; $h$ - height of the slope; $h_{i}-$ height of each strip; $h_{i a}$ - height of the hydrostatic level in each strip; $h$ ' ${ }_{i a}-$ height of the free water column above each strip; $\theta_{\mathrm{i}}-$ angle between normal and tangential components of the weight for each strip.

\section{Establishing the dependence between the flooding speed and the stability of the waste dump's slope}

Determining the stability reserve in the case of a submerged slope at a given time, using relation no. 3 , does not give an image of what happens during the entire period necessary to flood the residual gap.

In order to solve this problem we started from a hypothetical situation, considering that the residual gap is formed between the slope of an interior dump with a height of $30 \mathrm{~m}$ and a slope angle of $27^{\circ}$ (natural slope angle) and a final slope of the lignite open pit with the same height and a $45^{\circ}$ inclination. The distance between the two slopes, measured at the base of the open pit, was considered to be $50 \mathrm{~m}$ (figure 1). 


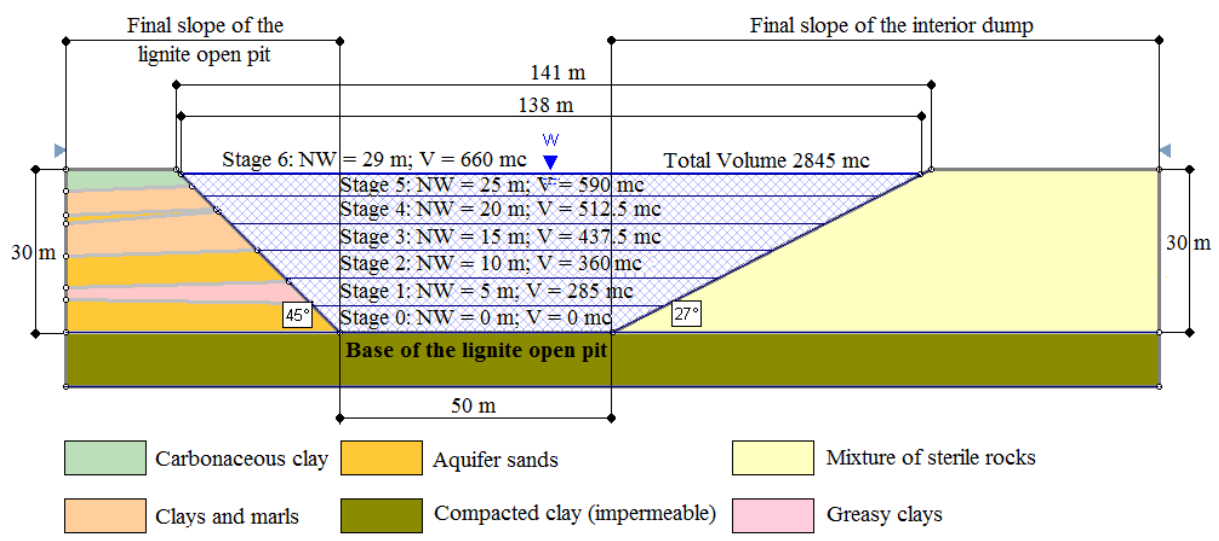

Fig. 1. Model of the residual gap of the former lignite open pit.

Then, we used data on the open pits and lakes formed in former lignite open pits from Oltenia mining basin. Thus, from the literature $[1,11,14]$, we analyzed data concerning the geotechnical characteristics of the waste rocks (at natural and saturated humidity), the hydraulic gradients, the specific flows of the aquifer horizons intercepted by the mining works (the underground water inflow), the multiannual average rainfall, respectively, multiannual average evapotranspiration.

Based on these analyses, the following values were considered:

- Physical and geotechnical characteristics of waste rocks: $\gamma_{\mathrm{v}}=17.87 \mathrm{kN} / \mathrm{m}^{3} ; \mathrm{c}=13.45 \mathrm{kPa}$; $\varphi=23.46^{\circ}$;

- Hydraulic gradient: $\mathrm{I}_{\min } \leq 0.02 ; \mathrm{I}_{\operatorname{med}}=0.04 \div 0.05 ; \mathrm{I}_{\max } \geq 0.07$;

- Average specific flow of the aquifers: $5.645 \mathrm{~m}^{3} / \mathrm{day} / \mathrm{m}$;

- Multiannual average rainfall/evapotranspiration: 750/735 mm/year.

Considering these data, it can be assumed that the supplementary water from rainfall is insignificant $\left(0.003 \mathrm{~m}^{3} / \mathrm{day} / \mathrm{m}\right)$, which is why the natural specific flow will be considered equal to the specific average flow of the aquifers.

Stability analyzes were carried out for the two described situations (using a specialized software), the natural and artificial (combined) flooding methods of the considered residual gap, taking into account the increase by $5 \mathrm{~m}$ of the water level in the lake in each stage (except for the last flooding stage where the increase of the water level is of $4 \mathrm{~m}$ ).

We mention that the values of the stability coefficients considered are valid for the slope of the interior dump (considering that it is much more vulnerable to landslides occurrence during the flooding process than the final slope of the lignite open pit). The value of the stability coefficient corresponding to stage 0 , in both situations, is the one determined under the initial conditions, when there is no water in the residual gap and the waste rocks from the interior dump are at natural humidity.

\subsection{Natural flooding}

In this situation, the specific flow available (the natural specific flow $=$ the specific average flow of the aquifers) to flood the residual gap of the former lignite open pit is considered constant. At the same time, as the water level increases, so does the opening of the residual gap (the distance between the final slope of the lignite open pit and the slope of the interior dump) and, consequently, the volume of water required for each flooding stage. In other words, the time required to raise the water level by $5 \mathrm{~m} \mathrm{(4} \mathrm{m}$ in the last stage) increases and, consequently, the flooding speed decreases (table 2). 
Table 2. Characteristic elements of the natural flooding process.

\begin{tabular}{|c|c|c|c|c|c|c|c|}
\hline \multicolumn{8}{|c|}{ Natural flooding } \\
\hline Stage & $\begin{array}{l}\text { NW } \\
{[\mathrm{m}]}\end{array}$ & $\begin{array}{c}\mathbf{Q}_{\text {nat }} \\
{\left[\mathrm{m}^{3} / \text { day } / \mathbf{m}\right]}\end{array}$ & $\begin{array}{c}\mathbf{V}_{\mathbf{u}} \\
{\left[\mathrm{m}^{3}\right]}\end{array}$ & $\begin{array}{c}t \\
\text { [days] }\end{array}$ & $\begin{array}{l}\text { NH } \\
{[\mathrm{m}]}\end{array}$ & $\begin{array}{c}\mathbf{v} \\
{[\mathrm{m} / \mathrm{day}]}\end{array}$ & $\mathbf{F}_{\mathrm{s}}$ \\
\hline 0 & 0 & 0 & 0 & 0 & 0 & 0 & 1.201 \\
\hline 1 & 5 & \multirow{6}{*}{5.645} & 285 & 50.49 & 6 & 0.099 & 1.103 \\
\hline 2 & 10 & & 360 & 63.77 & 14 & 0.078 & 1.021 \\
\hline 3 & 15 & & 437.5 & 77.50 & 20 & 0.065 & 1.019 \\
\hline 4 & 20 & & 512.5 & 90.79 & 27 & 0.055 & 1.085 \\
\hline 5 & 25 & & 590 & 104.52 & 29 & 0.048 & 1.283 \\
\hline 6 & 29 & & 660 & 116.92 & 29.8 & 0.034 & 1.468 \\
\hline Total & 29 & - & 2845 & 503.99 & 29.8 & - & - \\
\hline
\end{tabular}

Notations in table 2: NW - level of water in the lake; $Q_{\text {nat }}$ - average natural specific flow (average specific flow of the aquifers); $\mathrm{V}_{\mathrm{u}}$ - unitary volume (the volume specific for a $1 \mathrm{~m}$ thick section); $\mathrm{t}$ - time necessary to increase the water level in the lake by 5 respectively 4 $\mathrm{m}$ (or the increase in volume for each stage); $\mathrm{NH}$ - hydrostatic level in the waste dump; $\mathrm{v}-$ flooding speed characteristic for each stage; $F_{s}-$ stability coefficient characteristic to each flooding stage.

This increase in the time required to raise the water level by $5 \mathrm{~m} \mathrm{(4} \mathrm{m}$ in the last stage) leads to a longer period of time where the rocks from the dump are in contact with water. This situation allows the saturation of the rocks and the increase of the hydrostatic level in the body of the dump (due to the capillary pores that allow the water to rise into the dump's body, especially during stages 3 and 4 of the flooding process), without being counteracted by the hydrostatic pressure exerted by the water in the lake.

\subsection{Artificial (combined) flooding}

On the basis of the results obtained in the situation of natural flooding, namely that for the first flooding stage, which lasts approx. 50 days, results the lowest hydraulic gradient and the smallest difference between the level of the lake and hydrostatic level in the interior dump, for the artificial (combined) flooding of the residual gap was imposed this duration (50 days) for each rising stage of the lake's level (table 3).

Table 3. Characteristic elements of the artificial (combined) flooding process.

\begin{tabular}{|c|c|c|c|c|c|c|c|c|}
\hline \multicolumn{9}{|c|}{ Artificial (combined) flooding } \\
\hline Stage & $\begin{array}{l}\text { NW } \\
{[\mathrm{m}]}\end{array}$ & $\begin{array}{c}\mathbf{Q}_{\text {nat }} \\
{\left[\mathrm{m}^{3} / \mathbf{d a y} / \mathbf{m}\right]}\end{array}$ & $\begin{array}{c}Q_{\text {add }} \\
{\left[\mathrm{m}^{3} / \text { day } / \mathbf{m}\right]}\end{array}$ & $\begin{array}{r}\mathbf{V}_{\mathbf{u}} \\
{\left[\mathbf{m}^{3}\right]}\end{array}$ & $\begin{array}{c}\text { t } \\
\text { [days] }\end{array}$ & $\begin{array}{l}\text { NH } \\
{[\mathrm{m}]}\end{array}$ & $\begin{array}{c}\mathbf{v} \\
{[\mathrm{m} / \mathrm{day}]}\end{array}$ & $\mathbf{F}_{\mathrm{s}}$ \\
\hline 0 & 0 & 0 & 0 & 0 & 0 & 0 & 0 & 1.201 \\
\hline 1 & 5 & \multirow{6}{*}{5.645} & 0.055 & 285 & \multirow{6}{*}{50} & 6 & 0.100 & 1.103 \\
\hline 2 & 10 & & 1.555 & 360 & & 11 & 0.100 & 1.061 \\
\hline 3 & 15 & & 3.105 & 437.5 & & 16 & 0.100 & 1.091 \\
\hline 4 & 20 & & 4.605 & 512.5 & & 21 & 0.100 & 1.162 \\
\hline 5 & 25 & & 6.155 & 590 & & 26 & 0.100 & 1.312 \\
\hline 6 & 29 & & 7.555 & 660 & & 29.8 & 0.080 & 1.468 \\
\hline Total & 29 & - & - & 2845 & 300 & 29.8 & - & - \\
\hline
\end{tabular}

Notations in table 3: NW; $\mathrm{Q}_{n a t} ; \mathrm{V}_{\mathrm{u}} ; \mathrm{t} ; \mathrm{NH} ; \mathrm{v} ; \mathrm{F}_{\mathrm{s}}$ - same as in table 2; $\mathrm{Q}_{\text {add }}-$ supplementary specific water flow (from adductions).

Under this hypothesis, knowing the volume of water required to raise the water level by $5 \mathrm{~m}$ in each stage ( $4 \mathrm{~m}$ in the last stage) in the residual gap of the former lignite open pit (lake) and the specific flow from natural sources, it is possible to determine the specific flow required from adductions so as to obtain equal flooding times for each stage. These times shall be set so that the contact period of the unsaturated rocks from the interior dump with the water in the lake does not allow the hydraulic gradient to rise beyond a critical 
value. Also, this contact time must ensure a minimum (virtually constant) value between the water level in the lake and the hydrostatic level in the body of the interior dump. In this way the hydrostatic pressure exerted by the water in the lake can counteract the negative effects generated by the infiltrated water in the body of the interior dump (the deterioration of the physico-mechanical characteristics and the manifestation of the pore water pressure inside the mixture of waste rocks).

It can be seen from table 3 that in the last stage of flooding, because the rise in the water level is of only $4 \mathrm{~m}$, while the time is the same, 50 days, there is a decrease in the flooding speed from 0.10 to $0.08 \mathrm{~m} /$ day.

The difference between the water level in the lake and the hydrostatic level in the dump remains constant for the first 5 stages $(1 \mathrm{~m})$ and decreases to $0.8 \mathrm{~m}$ in the last flooding stage (the hydraulic gradient is kept to a minimum).

\subsection{Results interpretation}

Based on the values presented in tables 2 and 3, the graphs in figure 2 were constructed showing the dependence between the values of the stability coefficient and the flooding speed, respectively the duration of the flooding process.
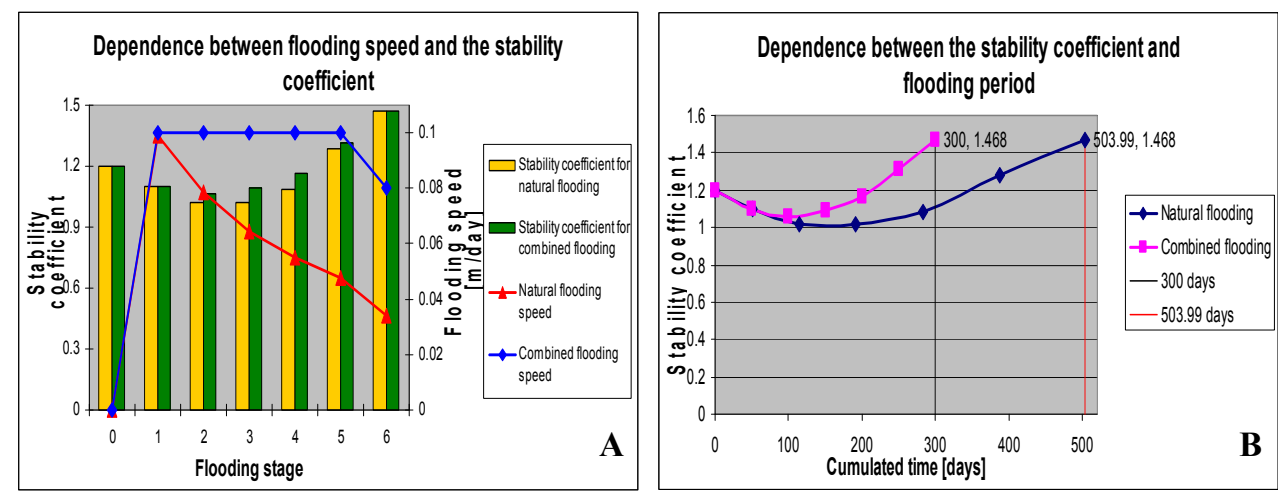

Fig. 2. Influence of flooding speed (A) and duration (B) on the stability coefficient.

From the graph presented in figure 2 A the following can be observed:

- In flooding stages 0,1 and 6 the values of the stability coefficients are identical because the situation of the residual gap is similar (the same water level in the lake and hydrostatic level in the dump);

- In the case of natural flooding, the value of the stability coefficient decreases between stages $0 \div 3$, while for the combined flooding this decrease occurs only between stages $0 \div$ 2 ;

- In the critical area, between stages $1 \div 4$ (Fs $\leq 1.2)$ it can be observed that the value of the stability coefficients in the case of combined flooding are higher by up to $6.6 \%$;

- In the last two stages of the flooding process, irrespective of the applied method and the flooding speed, there is an increase of the values of the stability coefficients above the initial value (from stage 0). This is explained by the fact that the hydrostatic level in the dump is nearing the maximum while the water level in the lake continues to increase. Thus the pressure of the pore water is exceeded by the hydrostatic pressure exerted on the slope by the water in the lake.

From the graph presented in figure $2 \mathrm{~B}$, it can also be observed that in the case of combined flooding, in the critical stages $(1 \div 4$, where Fs $\leq 1.2)$, the values of the stability coefficient are higher than those determined in the case of natural flooding. 
This finding, corroborated with the shorter flooding time, with approx. $40 \%$ (in the case of combined flooding), leads to the conclusion that the risk of a landslide during the combined flooding is substantially lower than in the case of natural flooding (the critical phase between stages $1 \div 4$ is lower as extension over time and the values of the stability coefficients are superior).

\section{Conclusions}

The appropriate flooding solution of residual gaps of former lignite open pits is chosen so that the process is technically and economically efficient, taking into account the destination of the newly formed lake, the benefits it brings and the need to put it into operation in the shortest period, but first of all, the safety and security conditions.

The general conclusion that can be drawn following the research carried out in the present study is that the evolution of the stability coefficient of the final slope of the interior dump depends directly on the flooding speed of the residual gap and on the duration of the process.

Based on this conclusion, we recommend that the flooding of the residual gaps of former lignite open pits to be carried out by the combined method, even if it entails additional costs. We also underline the fact that by increasing the flooding speed of the residual gap allows taking over the designed function of the newly formed lake in a much shorter period of time (up to $40 \%$ shorter).

The research presented in this paper has been conducted within the RAFF project (Risk Assessment of Final Pits During Flooding) co-financed by the Research Fund for Coal and Steel (RFCS) under the Grant Agreement No-847299-RAFF.

\section{References}

1. M. Lazăr, F. Faur, Mining Revue, 18 (2), 18-22 (Universitas, Petrosani, 2012)

2. I. Rotunjanu, Natural and artificial slope stability (in Romanian), (Infomin, Deva, 2005)

3. M. Lazăr, F. Faur, Stability and arrangement of slopes. Examples of calculation (in Romanian), (Universitas, Petroșani, 2015)

4. A. Bajcar, Stability of final slopes during the liquidation phase of open-cast brown coal mines (in Polish) (Wrocław, 2008)

5. K.J. Pierschke, B. Boehm, Geomechanical and water management aspects of the residual design in the Rhenish lignite mining area. Braunkohle (in German), 6 (1996)

6. E. Moraiti, B. Christaras, R. Brauer, Bulletin of the Geological Society of Greece, 43, 1267-1271 (ePublishing, 2010)

7. M. Cała, F. von Bismarck, M. Illing, Geotechnical and environmental aspects of recultivation and revitalization of post-mining landscapes in Poland and Germany (in German) (AGH, Krakow, 2014)

8. J. Szczepiński, J. Fiszer, Z. Stachowicz, P. Szczepanik, Biuletyn PIG 441, 167-174 (Warszawa, 2010)

9. J. Szczepiński, 11th International Mine Water Conference. An Interdisciplinary Response to Mine Water Challenges, 4-8 (Xuzhou, China, 2014)

10. S. Castagna, G.A. Dino, M. Lasagna, D.A. de Luca, Engineering Geology for Society and Territory, 5, 71-74 (Springer, New York, London, 2015)

11. D. Fodor, A. Smeu, Annals of the University of Petrosani, Mining Engineering, 14, 171-186 (Universitas, Petrosani, 2013)

12. M. Lazăr, Rehabilitation of degraded terrains (in Romanian), (Universitas, Petroşani, 2010)

13. M. Stănciucu, Stability of slopes (in Romanian), (Technical, Bucharest, 2018)

14. I.M. Apostu, F. Faur, Research Journal of Agricultural Science, 50 (4), 17-27 (Agroprint, Timisoara, 2018) 